\title{
Methanol fraction of Calliandra portoricensis root bark activates caspases via alteration in mitochondrial viability in vivo
}

\author{
Olubukola T. Oyebode ${ }^{1^{\circledR}}$, Jude O. Akinyelu², Emmanuel A. Oamen ${ }^{1}$, Olufunso O. Olorunsogo ${ }^{1}$ \\ ${ }^{1}$ Laboratories for Biomembrane and Biotechnology Unit, Department of Biochemistry, College of Medicine, University of Ibadan, Ibadan, Oyo State, \\ Nigeria \\ ${ }^{2}$ Department of Biochemistry, School of Life Sciences, University of Kwazulu Natal, KwaZulu-Natal, South Africa
}

\section{A R T I CLE I N F O}

Article Type:

Original Article

\section{Article History:}

Received: 2 April 2018

Accepted: 26 July 2018

\section{Keywords:}

Apoptosis

Mitochondria

Calliandra portoricensis

Caspases

mPT pore

\begin{abstract}
A B S T RAC T
Introduction: Dysregulated apoptosis is associated with a number of disease conditions. Traditionally, Calliandra portoricensis is used in the management of prostate enlargement. This study investigates the in vivo effect of potent methanol fraction of C. portoricensis (MFCP) on mitochondrial permeability transition $(\mathrm{mPT})$ pore, an important pharmacological target in treatment of various diseases, and examines the toxicities associated with its oral administration. Methods: Forty-two male Wistar strain rats $(70-80 \mathrm{~g})$ were divided into 6 groups of 7 animals each. Each group was orally administered 25, 50, 100, 200, $400 \mathrm{mg} / \mathrm{kg}$ MFCP and the control group received distilled water for 21 and 30 days, respectively. $\mathrm{mPT}$, assay for serum enzymes and hematological parameters were assessed spectrophotometrically while activation of caspases 3 and 9 was done by ELISA technique. Histological assessment of vital organs (liver, kidney, prostate) was carried out according to standard procedures.

Results: There were no significant effects on $\mathrm{mPT}$ pore at all doses administered after 21 days of oral administration. However, after 30 days of administration, MFCP induced mPT pore opening at doses 100 and $200 \mathrm{mg} / \mathrm{kg}$ with induction folds of 2.6 and 3.3, respectively while there was no induction of $\mathrm{mPT}$ pore opening at lower doses of $25 \mathrm{mg} / \mathrm{kg}$ and $50 \mathrm{mg} / \mathrm{kg}$. Furthermore, significant $(P<0.05)$ increases in serum enzymes (ALT, AST) were observed at all doses administered when compared with control after 30 days of oral administration. Cell counts (Hb, PCV, RBC, WBC) were adversely affected at the highest dose $(200 \mathrm{mg} / \mathrm{kg})$ compared with control and other treated groups $(25,50$ and $100 \mathrm{mg} / \mathrm{kg}$ ) after 30 days of administration. Similarly, activation of caspases 9 and 3 were observed in rat liver homogenate at high doses of the fraction while histological evaluation showed degeneration and distortion of organs at the highest dose.

Conclusion: MFCP contains phytochemicals that elicit the opening of the pore and induction of mitochondrial-mediated apoptosis. This would be relevant in treatment of degenerative diseases that results from down-regulation of apoptosis. However, caution should be exercised in using high doses of the plant.
\end{abstract}

Implication for health policy/practice/research/medical education:

High doses and prolonged use of the C. portoricensis decoction in treatment of diseases is discouraged given the potential harm it poses on the organs of the body. Isolation of the cell death-inducing phytochemical in the plant will be useful in the treatment of diseases characterized by low apoptosis.

Please cite this paper as: Oyebode OT, Akinyelu OA, Oamen EA, Olorunsogo OO. Methanol fraction of Calliandra portoricensis root bark activates caspases via alteration in mitochondrial viability in vivo. J Herbmed Pharmacol. 2018;7(4):251-258. doi: 10.15171/jhp.2018.38.

\section{Introduction}

A cell's decision to give up its entire life following insults arising from within the cell or its immediate environment proceeds via a physiological process called apoptosis (programmed cell death) (1). Apoptosis is involved in development, removal of infected, damaged and wornout/aged cells that have outlived their functions, thus playing a major role in maintaining the body's cellular homeostasis (2). Programmed cell death may involve the ligation of cell death receptors with their cognate ligands 
following induction of a death signal from outside $(3,4)$. This is referred to as extrinsic pathway. On the other hand, apoptosis may proceed via the intrinsic (mitochondrialmediated) pathway which requires alteration in the permeability of the inner mitochondrial membrane which results in swelling of the matrix leading to the release of apoptogenic proteins such as cytochrome $\mathrm{C}$ via the opening of the mitochondrial permeability transition (mPT) pore (5). The release of cytochrome $\mathrm{C}$ into the cytosol facilitates its binding to apoptotic protease activating factor-1 (APAF-1) which assembles the apoptosome and becomes a platform upon which pro-caspase -9 , the mitochondrial initiator caspase, is recruited and activated. Activated caspase-9 activates executioner caspase-3 via a caspase-cascade mechanism (6). Cysteine-dependent aspartate specific proteases (CASPASES) are responsible for the morphological features exhibited by a dying cell such as membrane blebbing and cell shrinkage (7). Hence, the release of cytochrome $\mathrm{C}$ via the opening of the $\mathrm{mPT}$ pore is crucial for caspase activation and subsequently cell death.

Given that mitochondria contribute to and accelerate the apoptotic process, molecular checkpoints are being targeted to regulate this important physiological process (8). In this regard, the mPT pore has become a strategic target in diseases involving dysregulated apoptosis. Certain bioactive agents present in medicinal plants elicit their chemo-protective effects through the induction or inhibition of the opening of $\mathrm{mPT}$ pore e.g. honokiol, magnolol $(9,10)$.

Calliandra is a genus of flowering plants in the subfamily Mimosaceae under the family Leguminoseae (Pea family). Calliandra portoricensis is a distinctive ornamental shrub and medicinal plant. Its local names in Nigeria are 'Tude' in Yoruba, 'Ule' in Igbo and 'Oga' in Hausa. The plant has also been reported to have anticonvulsant $(11,12)$ antidiarrheal, antispasmodic, antipyretic, antirheumatic and analgesic (13) activities in humans. Besides, Moharram et al (14) reported that $C$. portoricensis has antioxidant and anti-bacterial properties. The plant has been shown to have protective effects (antidote) in Wistar rats challenged with snake venom (15). In folklore medicine, it is used in combination with Plumbago zeylanica in the traditional treatment of prostate tumor. Results of phytochemical screening revealed that methanol fraction of the root bark of C. portoricensis contains cardiac glycosides, anthraquinones, flavonoids, phenols, saponins, steroids and tannins. Our preliminary data reveals that methanol fraction of C. portoricensis (MFCP) is potent with respect to induction of opening of the $\mathrm{MPT}$ pore, enhancement of mitochondrial ATPase activity and activation of cytochrome $\mathrm{C}$ in vitro (16). Owing to the relevance of bioavailability of the compound of interest at the target site and to determine the safety dose regimen for the potent methanol fraction, in vivo assessment of the efficacy of the potent MFCP in induction of $\mathrm{mPT}$ pore opening, activation of caspases and the determination of its toxic effects in normal rat were investigated.

\section{Materials and Methods}

Dosing of experimental animals

Doses of 25, 50, 100, 200 and $400 \mathrm{mg} / \mathrm{kg}$ were selected based on a preliminary study. Dosing was once daily over the experimental period and the oral route of administration was used because it is the intended human exposure route.

\section{Chemicals and reagents}

$\mathrm{N}$-2-hydroxy-ethyl-pipe-arizine-N-2-ethanesulfonic acid (HEPES), sucrose, rotenone, spermine, Bovine Serum Albumin (BSA), mannitol and all other reagents were purchased from Sigma-Aldrich chemical Co. (St. Louis, MO, USA) and were of the highest purity grade. Caspases 9 and 3 ELISA kits were obtained from Elabscience Biotechnology, Ltd China.

Collection and extraction of plant material Freshly harvested roots of C. portoricensis were obtained from Oje market, Ibadan, Oyo State, Nigeria. Samples were identified and authenticated at the Department of Botany, University of Ibadan and a specimen Voucher no. UIH-22466 was deposited in the Herbarium. The roots were washed, the bark peeled and air-dried for three weeks in the laboratory after which they were powdered and weighed, air-dried, powdered root bark of $C$. portoricensis $(2 \mathrm{~kg}$ ) was soaked with sufficient methanol in all- glass jars at room temperature for 72 hours. The filtrate was concentrated under reduced pressure using a rotary evaporator.

Partitioning of crude methanol extract of Calliandra portoricensis (MECP) using vacuum liquid chromatography Four grams silica gel $60(0.040-0.063 \mathrm{~mm}$, Merck) were adsorbed to $4 \mathrm{~g}$ MECP. The mixture was air-dried to obtain a powdery form. A sintered funnel for vacuum liquid chromatography (VLC) was packed with $8 \mathrm{~g}$ Silica gel (Hopkins and Williams, England). Solvents were added in order to increase polarity and n-hexane chloroform, ethyl acetate and methanol fractions were obtained in this order. The eluted fractions were concentrated using rotary evaporator under reduced pressure and the resulting concentrated solvent-free fractions were stored in glass sample bottles and stored at $4^{\circ} \mathrm{C}$.

\section{Isolation of rat liver mitochondria}

Rat liver mitochondria were isolated essentially according to modified method by Johnson Lardy (17). The nuclear fraction and cellular debris were pelleted by centrifuging the homogenate twice at $2300 \mathrm{rpm}$ for 5 minutes. The supernatant obtained was spun at $13000 \mathrm{rpm}$ for 10 
minutes to obtain the mitochondrial pellet which was washed twice with washing buffer by spinning at 12000 rpm for 10 minutes. The mitochondria obtained were immediately resuspended in appropriate volume of MSH buffer, and dispensed into Eppendorf tubes and kept at $4^{\circ} \mathrm{C}$ and used fresh.

Mitochondrial protein estimation

Mitochondrial protein was determined according to the method of Lowry et al (18) using BSA as standard.

Mitochondrial swelling assay

Mitochondrial permeability transition was determined according to the method of Lapidus and Sokolove (19). This was monitored by measuring the changes in absorbance of mitochondria at $540 \mathrm{~nm}$ in the presence and absence of calcium ion (triggering agent) in a Spectrumlab $752 \mathrm{~s}$ uv/visible spectrophotometer. Mitochondria (0.4 mg protein $/ \mathrm{mL}$ ) were pre-incubated in the presence of $0.8 \mu \mathrm{M}$ rotenone in a medium containing $210 \mathrm{mM}$ mannitol, 70 $\mathrm{mM}$ sucrose, $5 \mathrm{mM}$ HEPES-KOH ( $\mathrm{pH}$ 7.4) for 3 minutes prior to addition of $300 \mu \mathrm{M} \mathrm{CaCl}_{2}$, while $5 \mathrm{mM}$ succinate was added 30 seconds later and $\mathrm{mPT}$ was measured at 540 $\mathrm{nm}$ for 12 minutes at 30 seconds interval. The inhibitory effect of spermine on the induction of pore opening was carried out prior to addition of $\mathrm{CaCl}_{2}$. The inductive effects of fractions were monitored when the fractions were replaced with $\mathrm{CaCl}_{2}$

\section{Study design}

Forty-two male Wistar rats (70-80 g) were divided into 6 groups of 7 animals each. Each group was orally administered $25,50,100,200,400 \mathrm{mg} / \mathrm{kg}$ of the methanol fraction and the control group received distilled water for 21 and 30 days, respectively. For oral administration of MFCP for 30 days, the highest dosage group was $200 \mathrm{mg} /$ $\mathrm{kg}$. This may be due to toxicity of the extract because no animal survived the $400 \mathrm{mg} / \mathrm{kg}$ dose.

Sample preparation for caspase- 9 and 3 activities Livers were excised from male Wistar rats that were orally administered 25, 50,100, $200 \mathrm{mg} / \mathrm{kg}$ of the potent methanol fraction along with their control subjects. Each liver was weighed and rinsed with phosphate buffered saline thoroughly until a clear wash was obtained. The washed livers were then put in the sample bottles and frozen for 48 hours. After, they were brought out to thaw, the samples were then homogenized on ice and the homogenates were centrifuged at $8000 \mathrm{rpm}$ for 5 minutes. The supernatant obtained were then used for initiator caspases- 9 and executioner caspase- 3 analyses.

Determination of caspase -3 and 9 activities

Levels of caspase- 9 and 3 were determined using an ELISA (Elabscience Biotechnology, Ltd China) kit with pre-coated antibodies for CASP9 and CASP3, respectively. A microplate reader (DNM-9602A from china) was used to read optical density at $450 \mathrm{~nm}$.

Tissue preparation for histopathology

Liver, prostate and kidney were processed for histopathology. They were quickly removed, trimmed and placed in $10 \%$ formalin for about 5 days for proper fixation and dehydrated by ascending grades of isopropyl alcohol for an hour. The dehydrated organs were cleared in xylene and transferred into 2 changes of liquid paraffin wax. The tissue sections were stained in Ehrlich's hematoxylin for eight minutes, washed in tap water and dipped in acid alcohol to remove excess stain. These were counter stained in $10 \%$ aqueous eosin, incubated and mounted for photomicrography.

Assay of serum enzymes/determination of hematological parameters

Alanine aminotransferase (ALT) and aspartate aminotransferase (AST) were measured by monitoring the concentration of pyruvate hydrazone formed according to the method described by Reitman and Frankel (20). Hemoglobin, packed cell volume red blood cell count and white blood cell counts were determined by the method described by Jain (21).

\section{Results}

Effects of various doses of methanol fraction (MFCP) on rat liver $\mathrm{mPT}$ pore in the absence and presence of calcium (21 \& 30 days)

Mitochondria were isolated from control animals and mitochondrial swelling assay was carried out. There was no significant change in the volume of mitochondria respiring on succinate in the presence of rotenone in the mitochondria of untreated animals for 21 and 30 days (Figure 1).

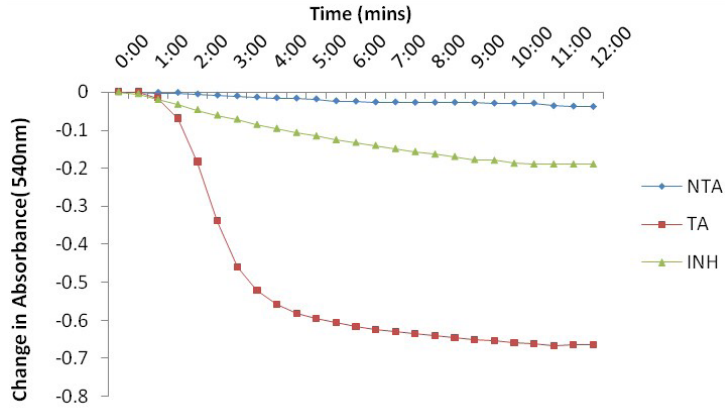

Figure 1. Representative profiles of changes in absorbance (540 $\mathrm{nm}$ ) of cyclosporine A reversed calcium-ion induced mitochondrial membrane permeability transition pore opening (Untreated Animals $-21 \& 30$ days).

NTA- Non triggering agent. TA, triggering agent. INH, Inhibitor (Cyclosporine A).

*Typical data of one experiment are shown and similar results were obtained in at least 3 different preparations. 
Figures 2 and 3 show the profiles of changes in absorbance of mitochondria at various doses of MFCP following oral administration for 21 and 30 days in the absence of calcium. These results show that after 21 days of oral administration of MFCP, there were no significant effect on $\mathrm{mPT}$ pore in the absence of calcium at all doses administered. However, after 30 days of administration, MFCP induced $\mathrm{mPT}$ pore opening in the absence of calcium at 100 and $200 \mathrm{mg} / \mathrm{kg}$ with induction folds of 2.6 and 3.3, respectively. However, there was no induction of $\mathrm{mPT}$ pore opening at lower doses of $25 \mathrm{mg} / \mathrm{kg}$ and $50 \mathrm{mg} /$ $\mathrm{kg}$, while the animals could not survive the highest dose of $400 \mathrm{mg} / \mathrm{kg}$ for 30 days.

Figures 4 and 5 show the profile of changes in absorbance of mitochondria at various doses of MFCP following oral administration for 21 and 30 days respectively, in the

\section{Time(mins)}

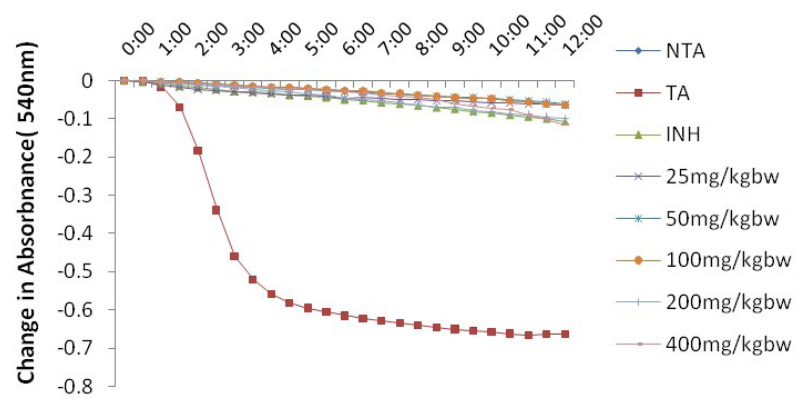

Figure 2. Representative profiles of changes in absorbance of mitochondria at various doses $(25,50,100,200$ and $400 \mathrm{mg} / \mathrm{kg}$ ) of MFCP over a period of 12 minutes in the absence of calcium (21 days). NTA, non triggering agent; TA, triggering agent; INH, Inhibitor (cyclosporine A).

*Typical data of one experiment are shown and similar results were obtained in at least 3 different preparations.

\section{Time(mins)}

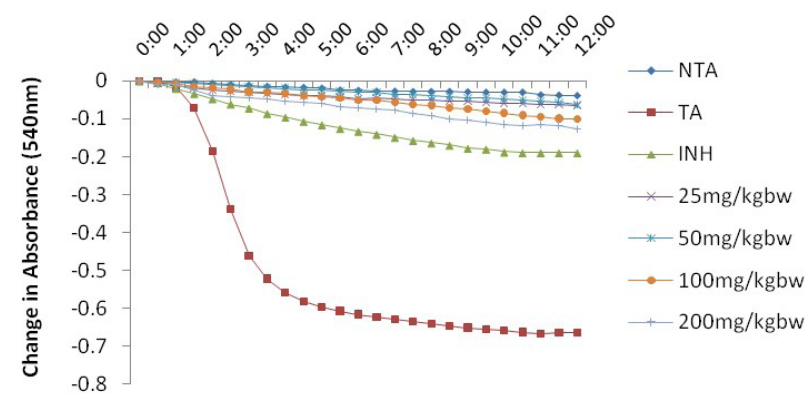

Figure 3. Representative profiles of changes in absorbance of mitochondria at various doses $(25,50,100$ and $200 \mathrm{mg} / \mathrm{kgbw})$ of MFCP over a period of 12 minutes in the absence of calcium (30 days). NTA, non triggering agent; TA, triggering agent ( $3 \mathrm{mM}$ $\mathrm{CaCl}_{2}$ ); INH, Inhibitor (cyclosporine A).

${ }^{*}$ Typical data of one experiment are shown and similar results were obtained in at least 3 different preparations. presence of calcium. The results revealed that calcium potentiated $\mathrm{mPT}$ pore opening of rat liver at doses of 200 and $400 \mathrm{mg} / \mathrm{kg}$ after 21 days of oral administration. In this regard, the induction folds of 10.6 and 10.9 were obtained at doses $200 \mathrm{mg} / \mathrm{kg}$ and $400 \mathrm{mg} / \mathrm{kg}$, respectively while calcium gave a 10.5 fold increase. Oral administration of lower doses of 25,50 and $100 \mathrm{mg} / \mathrm{kg}$ had an inductive effect of 10.1, 10.2, 10.4 folds, respectively. Overall, the inductive effect was concentration-dependent. According to the figure, after 30 days of administration, the effect on $\mathrm{mPT}$ induction was greatly potentiated by MFCP in the presence of calcium at 100 and $200 \mathrm{mg} / \mathrm{kg}$ with induction folds of 17.6 and 19.0, respectively. Induction of $\mathrm{mPT}$ pore opening was also observed at doses 25 and $50 \mathrm{mg} / \mathrm{kg}$ with inductive folds of 16.8 and 17.0 while calcium gave a 17.1fold increase.

\section{Time(mins)}

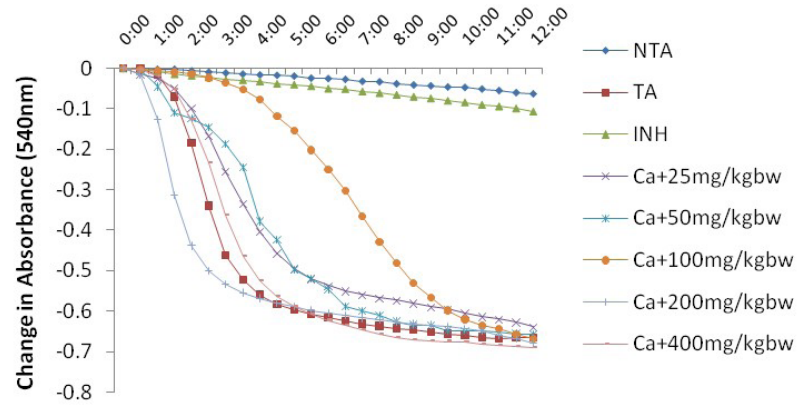

Figure 4. Representative profile of changes in absorbance of mitochondria at various doses $(25,50,100,200$ and $400 \mathrm{mg} /$ kgbw) of MFCP over a period of 12 minutes in the presence of calcium (21 days). NTA, non triggering agent; TA, triggering agent $(3 \mathrm{mM} \mathrm{CaCl})$; INH, Inhibitor (cyclosporine A).

*Typical data of one experiment are shown and similar results were obtained in at least 3 different preparations.

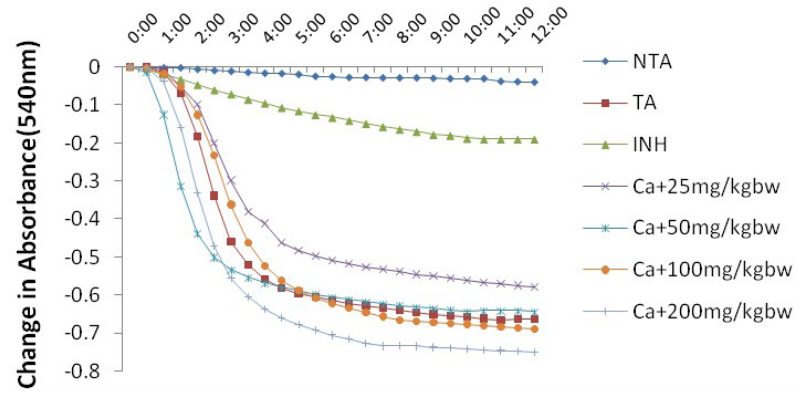

Figure 5. Representative profile of changes in absorbance of mitochondria at various doses $(25,50,100$ and $200 \mathrm{mg} / \mathrm{kgbw})$ of MFCP over a period of 12 minutes in the presence of calcium (30 days). NTA, non triggering agent; TA, triggering agent (3mM $\mathrm{CaCl}_{2}$ ); INH, Inhibitor (cyclosporine A).

*Typical data of one experiment are shown and similar results were obtained in at least 3 different preparations. 
Effects of MFCP on hematological and liver enzymatic profiles in rats after 21 and 30 days of administration After 21 days of administration, the packed cell volume of the animals increased maximally at $50 \mathrm{mg} / \mathrm{kg}$ when compared with control. Similar effects were also observed for white blood cell (WBC) and red blood cell (RBC) count as well as hemoglobin levels. Decreases in the levels of WBC, RBC, PCV and $\mathrm{Hb}$ were observed at doses higher than $50 \mathrm{mg} / \mathrm{kg}$ (Figure 6).

Figure 7 shows the in vivo effect of oral administration of MFCP (30 days) on hematological parameters. Interestingly, there were significant declines $(P<0.05)$ in the hematological parameters (PCV, WBC, $\mathrm{RBC}$ and $\mathrm{Hb}$ ) of all the dosage groups $(25,50,100$ and $200 \mathrm{mg} / \mathrm{kg}$ ) when compared to the control group. In this regard, cell counts were adversely affected at the highest dose $(200 \mathrm{mg} / \mathrm{kg})$ compared with control and other treated groups $(25,50$ and $100 \mathrm{mg} / \mathrm{kg}$ ).

The in vivo effect of oral administration of MFCP

$(21$

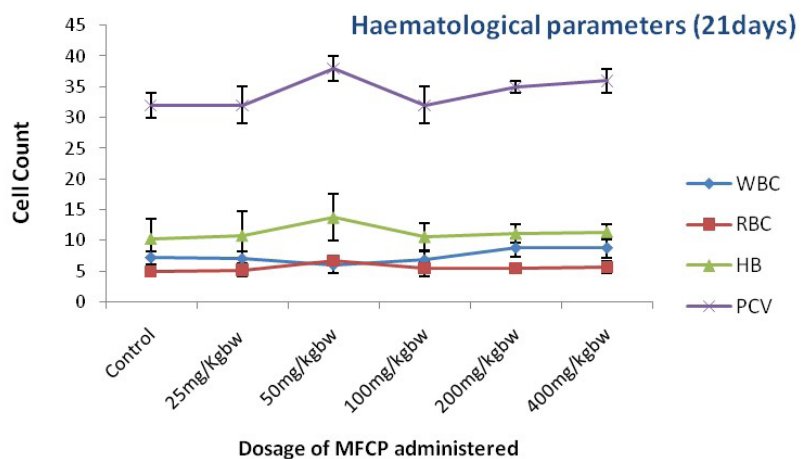

Figure 6. In vivo effect of oral administration of MFCP on Hematological parameters (21 days). WBC, white blood cell; $\mathrm{RBC}$, red blood cell; $\mathrm{HB}$, hemoglobin; $\mathrm{PCV}$, packed cell volume. Values are mean $\pm \mathrm{SD}$. $P<0.05$ vs control $\left({ }^{*}\right)$.

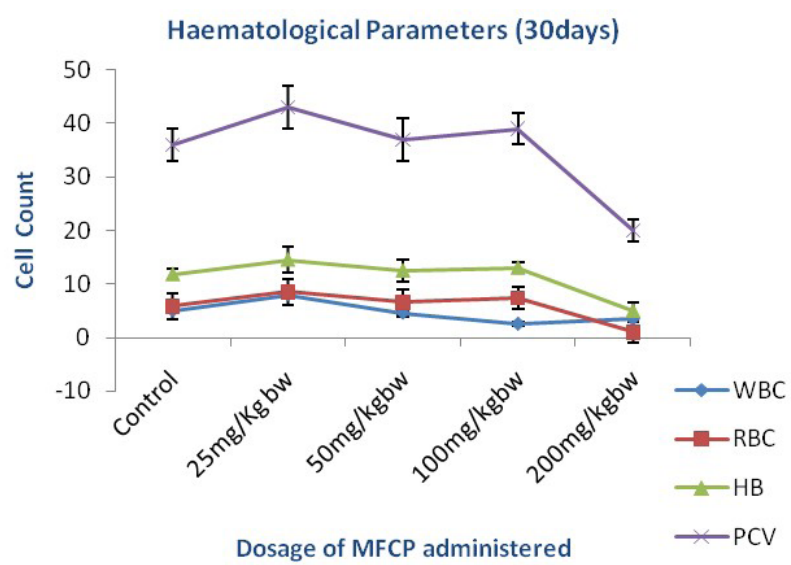

Figure 7. In vivo effect of oral administration of MFCP on Hematological parameters (30 days). WBC, white blood cell; RBC, red blood cell; HB, hemoglobin; PCV, packed cell volume. Values are mean \pm SD. $P<0.05$ vs control $\left({ }^{*}\right)$. days) on serum aminotransferases are depicted in Figure 8. According to the results, there were significant increases in the serum ALT and AST activity of 200 and $400 \mathrm{mg} / \mathrm{kg}$ dosage groups when compared to the control rats after 21 days of administration. However, at all doses of methanol fraction administered (25, 50, 100, $200 \mathrm{mg} /$ $\mathrm{kg}$ ), serum AST and ALT levels were significantly elevated when compared with the control after 30 days of oral administration of MFCP. The data is depicted in Figure 9.

Effects of oral administration of MFCP tissue sections (liver, kidney and prostate) after 30 days

Photomicrographs of liver sections are depicted in Figure 10. As the doses of methanol fraction administered increased, a moderate to severe diffuse vacuolar degeneration of hepatocytes were observed while control animals had very mild diffuse vacuolation.

Figure 11 shows the photomicrographs of kidney sections of Wistar rats following oral administration of methanol

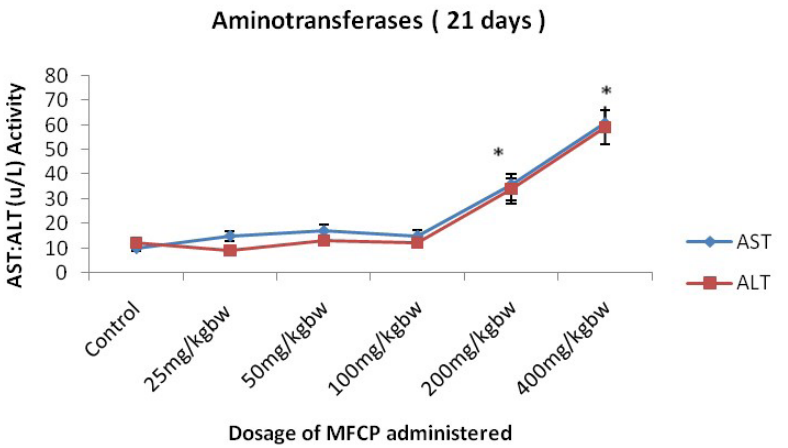

Figure 8. In vivo effect of oral administration of MFCP on serum aminotransferases (21 days). WBC, white blood cell; RBC, red blood cell; HB, hemoglobin; PCV, packed cell volume. Values are mean $\pm \mathrm{SD}$. $P<0.05$ vs control( $\left.{ }^{*}\right)$.

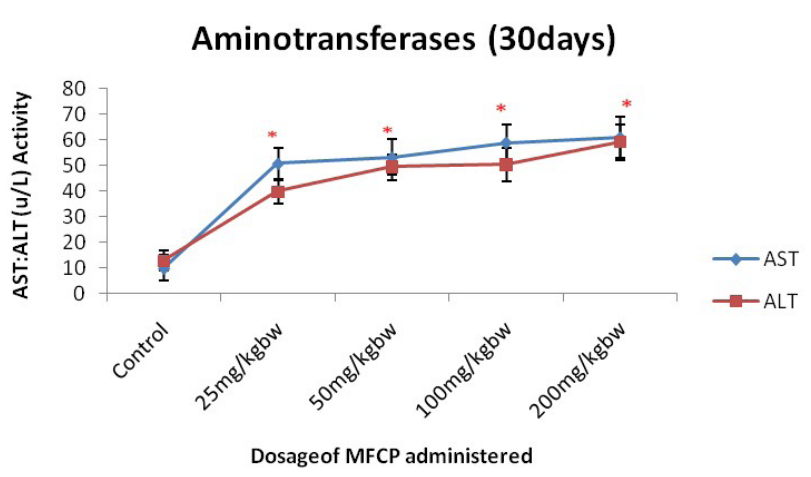

Figure 9. In vivo effect of oral administration of MFCP on liver enzymatic profile (30 days). WBC, white blood cell; RBC, red blood cell; HB, hemoglobin; PCV, packed cell volume. Values are mean $\pm \mathrm{SD}$. $P<0.05$ vs control $\left({ }^{*}\right)$. 

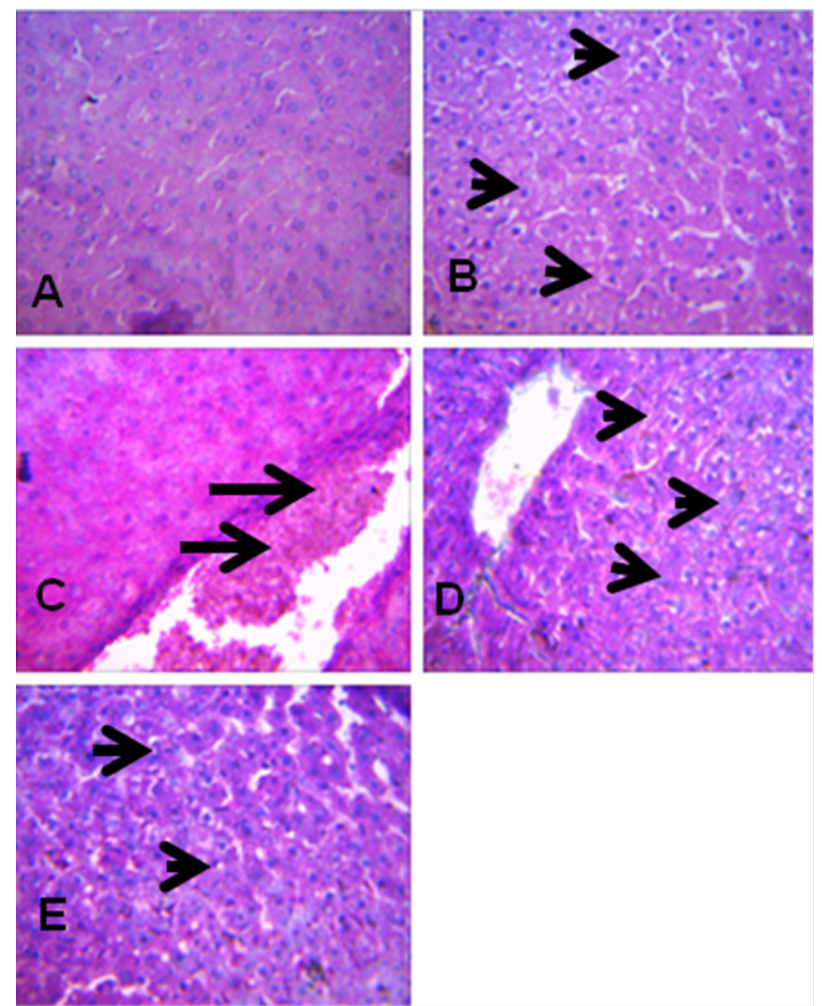

Figure 10. Photomicrographs of liver sections of animals orally administered MFCP for 30 days.(A ) control, (B) $25 \mathrm{mg} / \mathrm{kg}$ bw, (C) 50 $\mathrm{mg} / \mathrm{kg}$ bw, (D) $100 \mathrm{mg} / \mathrm{kg}$ bw, (E) $200 \mathrm{mg} / \mathrm{kg}$ bw (x400).

(A) Very mild diffuse vacuolation of hepatocytes, (B) Moderate vacuolar degeneration of hepatocytes, (C) Further vacuolation of hepatocytes, (D) Severe degeneration of hepatocytes.

fraction for 30 days. No visible lesions were observed in kidney of animals that received doses of 25, 50 and 100 $\mathrm{mg} / \mathrm{kg}$ MFCP. However, protein casts were abundant in kidneys of animals that received the highest dose of 200 $\mathrm{mg} / \mathrm{kg}$.

Photomicrographs of prostate sections of animals orally administered methanol fraction for 30 days are shown in Figure 12. As seen from the figure, glandular secretions were observed in the prostate of animals administered doses $50 \mathrm{mg} / \mathrm{kg}$ and $100 \mathrm{mg} / \mathrm{kg}$ while distortion of the entire gland was observed at the highest dose of $200 \mathrm{mg} / \mathrm{kg}$. In particular, at dose of $50 \mathrm{mg} / \mathrm{kg}$, lumen of the glandular units appeared shrunken but the epithelial glands appeared normal while necrotic debris were observed in the prostate of animals that received the highest dose of $200 \mathrm{mg} / \mathrm{kg}$. No visible lesion was observed in the prostate of control animals.

Oral administration of MFCP (30 days) activates caspases 3 and 9 activation

According to the data (Figure 13), increases in activities of caspases 9 and 3 were observed in liver homogenates of rats orally administered MFCP. In this regard, a 1.8-fold increase was observed at the highest dose $(200 \mathrm{mg} / \mathrm{kg})$ for caspase- 9 while a 2 -fold increase was recorded for caspase
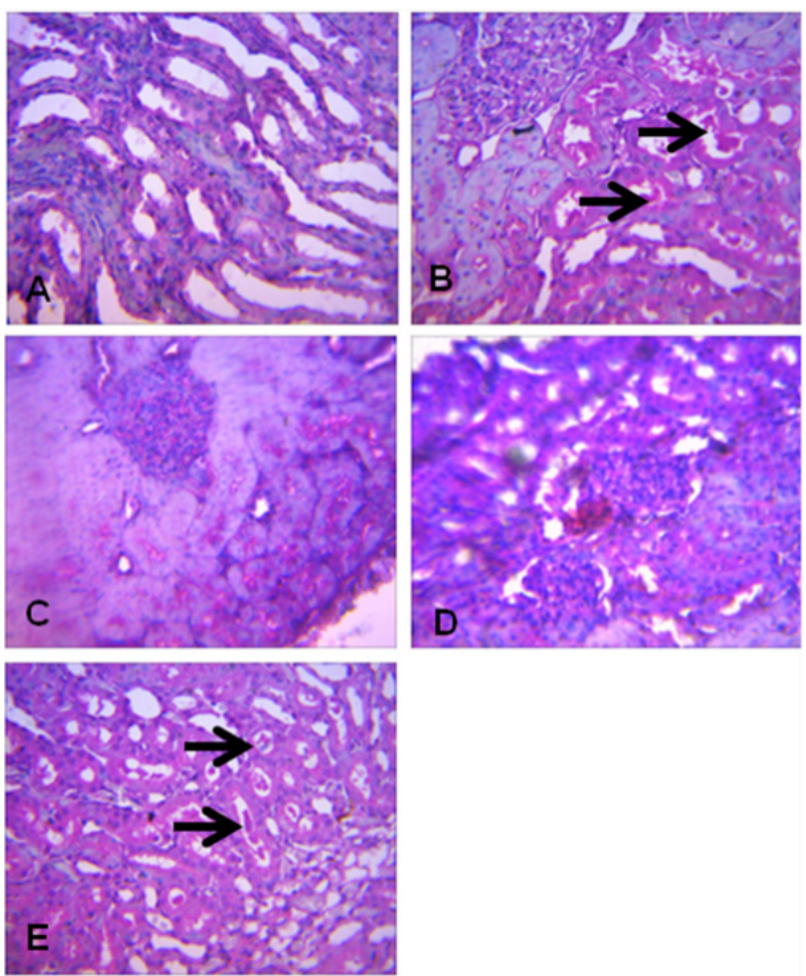

Figure 11. Photomicrographs of kidney sections of animals orally administered MFCP for 30 days. (A ) control, (B) $25 \mathrm{mg} / \mathrm{kg}$ bw, (C) 50 $\mathrm{mg} / \mathrm{kg} \mathrm{bw}$, (D) $100 \mathrm{mg} / \mathrm{kg}$ bw, (E) $200 \mathrm{mg} / \mathrm{kg}$ bw (x400).

(A) No visible lesions seen, (B) slightly few lesions observed, (C) No visible lesions, (D) Protein casts were observed.

3 at the same dose.

\section{Discussion}

Our preliminary data reveal the in vitro inductive effect of the potent MFCP on MPT pore in rat liver (16). We investigated the apoptotic potential of MFCP in rat liver mitochondria with the view of establishing safety regimens of the fraction in vivo. $\mathrm{mPT}$ was assessed spectrophotometrically in the animal at $540 \mathrm{~nm}$. The results obtained showed that the integrity of the mitochondria isolated from untreated animals were not compromised thus, they were suitable for further use. After 21 days of oral administration of MFCP, the methanol fraction had no effect whatsoever in inducing $\mathrm{mPT}$ at all doses tested. This might be due to poor oral bioavailability of the active principle of the fraction which is a potential drawback associated with dietary compounds after ingestion (22). However, after 30 days of administration, MFCP induced $\mathrm{mPT}$ pore opening in the absence of calcium at 100 and $200 \mathrm{mg} / \mathrm{kg}$ with induction folds of 2.6 and 3.3, respectively while there was no induction of $\mathrm{mPT}$ pore opening at doses lower than $50 \mathrm{mg} / \mathrm{kg}$. This inductive effect, though at higher doses, is in consonance with the in vitro data. These results suggest that at higher doses of methanol fraction, the active compound was available at 

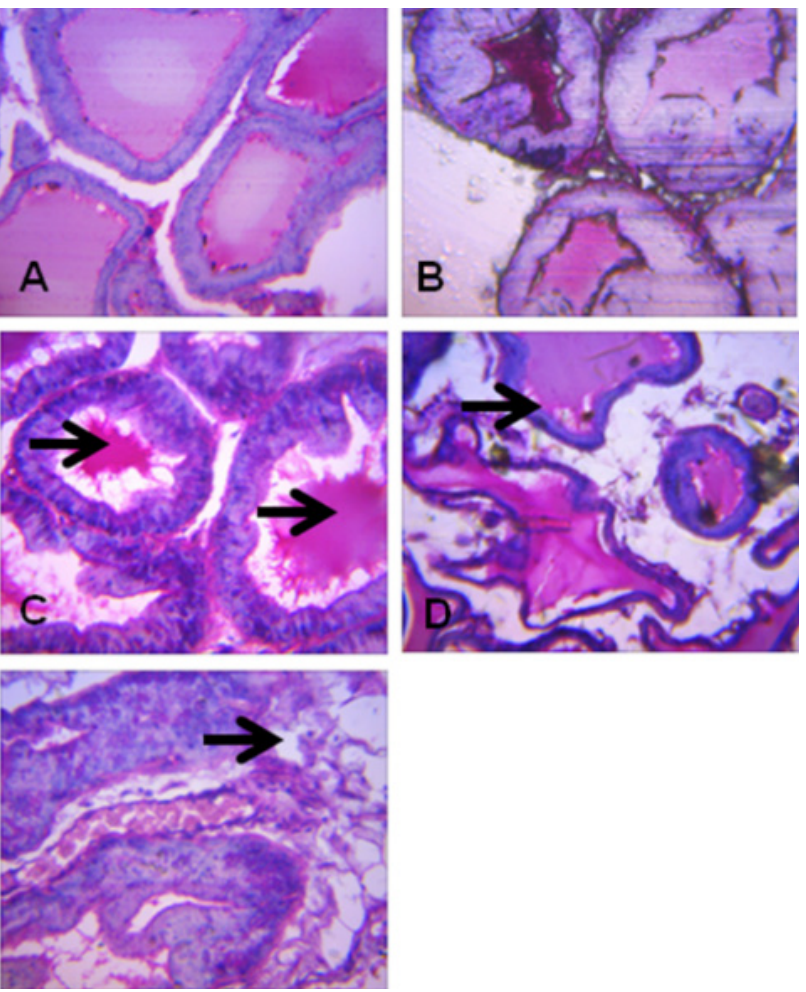

Figure 12. Photomicrographs of prostate sections of animals orally administered MFCP for 30 days. (A ) control, (B) $25 \mathrm{mg} / \mathrm{kg} \mathrm{bw}$, (C) 50 $\mathrm{mg} / \mathrm{kg}$ bw, (D) $100 \mathrm{mg} / \mathrm{kg}$ bw, (E) $200 \mathrm{mg} / \mathrm{kg}$ bw (x400).

(A) No visible lesions seen, (B) Glandular secretions seen, (C) Shrinkage of lumen of glandular units, (D) Necrotic debris/distortion of the entire gland.

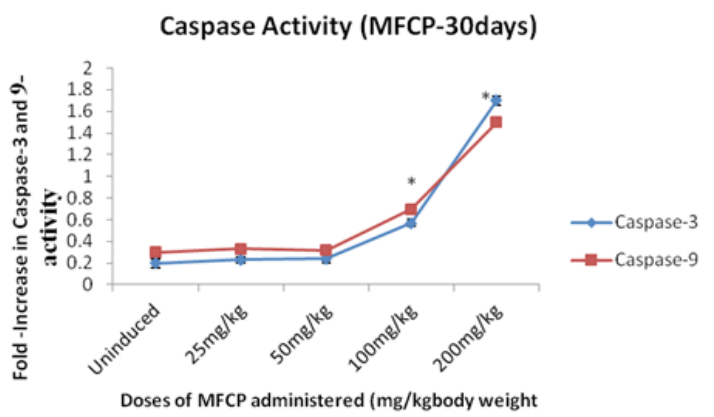

Figure 13. Effects of oral administration of methanol fraction for 30 days on caspase- 3 and 9 activities in rat liver homogenate. $P<0.05$ vs control.

the target site to interact with the components of the $\mathrm{mPT}$ pore in order to elicit inductive effect.

Furthermore, the data revealed that oral administration of higher doses of MFCP for 21 (200 and $400 \mathrm{mg} / \mathrm{kg}$ ) and 30 days ( 100 and $200 \mathrm{mg} / \mathrm{kg}$ ) potentiated calcium-induced opening of the pore. This suggests that methanol fraction elicited synergistic effect with calcium in inducing the opening of the $\mathrm{mPT}$ pore.

Investigation of the effects of methanol fraction on hematological parameters after oral administration revealed that the animals tolerated the fraction up to 50 $\mathrm{mg} / \mathrm{kg}$ after which decrease in levels of all hematological parameters (WBC, $\mathrm{PCV}, \mathrm{Hb}$, and $\mathrm{RBC}$ ) under investigation was observed, after 21 days of oral administration. Moreover, cell counts were adversely affected at the highest dose $(200 \mathrm{mg} / \mathrm{kg})$ compared with control and other treated groups $(25,50$ and $100 \mathrm{mg} / \mathrm{kg})$ after 30 days of administration. The decrease in hematological parameters observed may be associated with toxicity of the fraction at these doses. These findings suggest that MFCP could have hematotoxic effects which are also highly dependent on the dose and duration of administration.

Meyer and Harvey (23) had stated that serum enzyme levels could be indicative of liver function, hence, serum ALT and AST were determined spectrophotometrically. Our results showed that MFCP caused significant increases in the serum ALT and AST activities at 200 and $400 \mathrm{mg} / \mathrm{kg}$ bw dosage groups after twenty-one days of administration. However, serum AST and ALT levels were significantly elevated after thirty days of administration at all the test groups used for this study. These results suggest that MFCP may result in hepatic damage. However, the extent of damage is highly dependent on the dose and duration of administration. Hence, use of doses within therapeutic limits is instructive especially in the traditional and indiscriminate use of plant decoctions and extracts. Histopathological examination of liver, kidney and prostrate of animals orally administered MFCP for 30 days showed severe diffuse vacuolar degeneration of hepatocytes in livers of animals that received the highest dose $(200 \mathrm{mg} / \mathrm{kg})$. Similarly, protein casts were also abundant in kidneys of animals that received the highest dose of $200 \mathrm{mg} / \mathrm{kg}$, which suggests that the kidney tubules may be leaky to proteins, while no visible lesions were observed in kidneys of animals that received doses 25, 50, $100 \mathrm{mg} / \mathrm{kg}$ MFCP. Furthermore, distortion of the entire prostate gland as well as necrotic debris was observed in the prostates of animals that received the highest dose of $200 \mathrm{mg} / \mathrm{kg}$. Taken together, these observations suggest that MFCP could be toxic at higher doses, hence should be taken with caution.

Furthermore, activation of initiator caspase- 9 and executioner caspase- 3 was observed at $100 \mathrm{mg} / \mathrm{kg}$ and 200 $\mathrm{mg} / \mathrm{kg}$ dosage groups. However, there was no significant activation of caspase- 3 and 9 at lower dosage groups (25 and $50 \mathrm{mg} / \mathrm{kg}$ ). This is in consonance with our previous data that there was no induction of pore opening at these doses. The $\mathrm{mPT}$ is therefore a decisive event which defines the thin line between cell survival and death with mitochondrial membranes serving as a battlefield on which various signals combat to decide the fate of the cell (19).

\section{Conclusion}

In summary, these results demonstrate that MFCP- 
induced apoptosis was mediated by induction of the opening of $\mathrm{mPT}$ pore which resulted in the activation of caspases-9 and 3. This effect will be useful for evaluation of the potency of MFCP as an anti-tumor agent in prostate cancer cell lines. However, safety of the plant should be considered when administering for therapeutic purposes.

\section{Authors' contributions}

OTO, JOA and EAO carried out the experiments. OTO carried out statistical analysis and wrote the draft manuscript. OOO designed the experiment, supplied reagents and equipments and proofread the manuscript. All authors read and approved the manuscript.

\section{Conflict of interests}

The authors declare that they have no conflicting interests.

\section{Ethical considerations}

All experimental procedures conformed to the guidelines for research as recommended by University of Ibadan Animal Care \& Use Research Ethics Committee (Ethical code UI-ACUREC/17/0070).

\section{Funding/Support}

The authors financed this research project.

\section{References}

1. Kerr JF, Wyllie AH, Currie AR. Apoptosis: a basic biological phenomenon with wide-ranging implications in tissue kinetics. Br J Cancer. 1972;26(4):239-57.

2. Hassan M, Watari H, AbuAlmaaty A, Ohba Y, Sakuragi N. Apoptosis and molecular targeting therapy in cancer. Biomed Res Int. 2014;2014:150845. doi: 10.1155/2014/150845.

3. Ashkenazi A, Dixit VM. Death receptors: signaling and modulation. Science. 1998;281(5381):1305-8.

4. Locksley RM, Killeen N, Lenardo MJ. The TNF and TNF receptor superfamilies: integrating mammalian biology. Cell. 2001;104(4):487-501.

5. Adams JM. Ways of dying: multiple pathways to apoptosis. Genes Dev. 2003;17(20):2481-95. doi: 10.1101/gad.1126903.

6. Wang C, Youle RJ. The role of mitochondria in apoptosis. Annu Rev Genet. 2009;43:95-118. doi: 10.1146/annurevgenet-102108-134850.

7. Wyllie AH. "Where, O death, is thy sting?" A brief review of apoptosis biology. Mol Neurobiol. 2010;42(1):4-9. doi: 10.1007/s12035-010-8125-5.

8. Menbari MN, Rahmani SA, Ahmadi A, Zandi F, Bagheri $\mathrm{N}$, Jalili $\mathrm{A}$, et al. Evaluation of E-cadherin $(\mathrm{CDH} 1)$ gene polymorphism related to gastric cancer in Kurdish population. Life Sci J. 2013;10(12s):212-6.
9. Martin KR. Targeting apoptosis with dietary bioactive agents. Exp Biol Med (Maywood). 2006;231(2):117-29.

10. Millimouno FM, Dong J, Yang L, Li J, Li X. Targeting apoptosis pathways in cancer and perspectives with natural compounds from mother nature. Cancer Prev Res (Phila). 2014;7(11):1081-107. doi: 10.1158/1940-6207.capr-140136.

11. Adesina SK. Studies on some plants used as anticonvulsants in Amerindian and African traditional medicine. Fitoterapia. 1982;53(5):147-62.

12. Akah PA, Nwaiwu JI. Anticonvulsant activity of root and stem extracts of Calliandra portoricensis. J Ethnopharmacol. 1988;22(2):205-10.

13. Aguwa CN, Lawal AM. Pharmacologic studies on the active principles of Calliandra portoticensis leaf extracts. J Ethnopharmacol. 1988;22(1):63-71. doi: 10.1016/03788741(88)90231-0.

14. Moharram FA, Marzouk MS, Ibrahim MT, Mabry TJ. Antioxidant galloylated flavonol glycosides from Calliandra haematocephala. Nat Prod Res. 2006;20(10):927-34. doi: 10.1080/14786410500378494.

15. Onyeama H, Ebong PE, Eteng MU, Igile GO, Ibekwe HA, Atangwho IJ. Effects of Calliandra portoricensis extracts on the haematological indices of Wistar rats challenged with venom of Echis ocellatus. J Appl Pharm Sci. 2012;2(6):1404. doi: 10.7324/JAPS.2012.2610.

16. Oyebode TO, Adebusuyi OT, Akintimehin SE, Olorunsogo OO. Modulation of cytochrome $\mathrm{C}$ release and opening of mitochondrial permeability transition pore by Calliandra portoricensis (Benth) root bark methanol extract. European J Med Plants. 2017;20(1):1-14. doi: 10.9734/ EJMP/2017/35211.

17. Johnson D, Lardy $H$. Isolation of liver or kidney mitochondria. Methods Enzymol. 1967;10:94-6. doi: 10.1016/0076-6879(67)10018-9.

18. Lowry OH, Rosebrough NJ, Farr AL, Randall RJ. Protein measurement with the Folin phenol reagent. J Biol Chem. 1951;193(1):265-75.

19. Lapidus RG, Sokolove PM. Inhibition by spermine of the inner membrane permeability transition of isolated rat heart mitochondria. FEBS Lett. 1992;313(3):314-8.

20. Reitman S, Frankel S. A colorimetric method for the determination of serum glutamic oxalacetic and glutamic pyruvic transaminases. Am J Clin Pathol. 1957;28(1):56-63.

21. Jain NC. Schalm's Veterinary Haematology. 4th ed. Philadelphia: Lea \& Febiger; 1986.

22. Bansal SS, Goel M, Aqil F, Vadhanam MV, Gupta RC. Advanced drug delivery systems of curcumin for cancer chemoprevention. Cancer Prev Res (Phila). 2011;4(8):115871. doi: 10.1158/1940-6207.capr-10-0006.

23. Meyer DJ, Harvey JW. Veterinary Laboratory Medicine: Interpretation and Diagnosis. 2nd ed. Elsevier Saunders; 2004. 